\title{
Food insecurity in community-dwelling older Australians
}

\author{
Susan Quine* and Stephen Morrell \\ School of Public Health, Building A27, Faculty of Medicine, University of Sydney, New South Wales 2006, Australia
}

Submitted 4 January 2005: Accepted 14 June 2005

\begin{abstract}
Objective: To identify the extent of food insecurity (defined as running out of food in the last 12 months and being unable to afford to buy more) amongst older Australians, and the characteristics of those who experience this condition.

Design: Cross-sectional population survey.

Setting and subjects: Respondents $(n=8881)$ were community-dwelling older people (65 years and older) living independently in New South Wales, Australia, randomly sampled to participate in a computer-assisted telephone interview conducted during 1999-2000. The response rate was $71 \%$. Responses to a food insecurity questionnaire item were collected along with sociodemographic information, living arrangements, lifestyle and self-rated health. Univariate analyses and logistic regression modelling of factors for reporting food insecurity were conducted.

Results: Approximately one in 50 older people reported experiencing food insecurity in the previous 12 months attributable to inadequate finances. The analyses revealed that those at risk can be identified as more likely to report poorer health, limited financial resources, not owning their own home and living alone. Gender and age differences were also evident.

Conclusion: While only a minority of older Australians reported experiencing food insecurity attributable to inadequate finances, such people are at higher risk of malnutrition and associated morbidity. Food insecurity is an important public health and equity issue in older people that can be addressed through implementing appropriate income and social support policies.
\end{abstract}

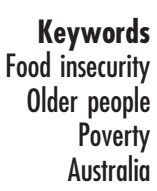

Food security has been defined as having access at all times to enough food for an active and healthy lifestyle ${ }^{1-3}$. Those without access to affordable sustenance through conventional channels have been described as experiencing food insecurity ${ }^{4,5}$. Food insecurity is an issue of a different order in Third World countries where sizeable minorities experience malnutrition and starvation on a daily basis ${ }^{6}$, yet relative deprivation exists in developed countries such as the $\mathrm{USA}^{7-9}$, Canada ${ }^{10,11}$ and England ${ }^{12}$, and is focused on here. Risk factors for food insecurity that limit household resources, or the proportion of those resources available for food acquisition ${ }^{13}$, are primarily poverty $^{14-17}$ and indicators of poverty such as unemployment and underemployment; being on a low income or in receipt of social security benefits or pensions; and where housing costs are high relative to income. Elderly people living alone and unable to leave their dwelling to shop for themselves, or who cannot prepare their food without assistance, are particularly vulnerable to poor nutritional status $^{18-25}$.

Some large-scale surveys of food insecurity have been conducted $^{7,8,11}$ but comparisons of prevalence are difficult due to different operational definitions, such as including compromised food quality rather than just food quantity, and restriction to specific causes of food insecurity. Some studies of food insecurity have focused on homeless people or the marginally housed ${ }^{23,26-28}$ and have tended to be small-scale and qualitative in approach, describing the personal experience of food insecurity ${ }^{20}$. While it is important to understand the impact of food insecurity on people's lives, it is also important to identify the magnitude of the problem and the characteristics of those who are affected on a population basis, in order to inform policy and service delivery ${ }^{29}$ to improve the health of older people $e^{30,31}$. The present paper aims to ascertain the extent of food insecurity attributable to inadequate finances experienced by older people in New South Wales, Australia, and to explore predictors of reporting such food insecurity. Given the data collected, the paper reports on the quantitative dimension of food insecurity - having enough to eat - rather than on the quality of the food or the psychological or social dimensions of food insecurity.

\section{Methods}

The findings reported here are from a representative population-based health and well-being survey of older people conducted in late 1999 and early 2000 by the 
New South Wales (NSW) Health Department. The Older Person's Health Survey (OPHS) ${ }^{32,33}$ used a computerassisted telephone interview method to interview more than 9000 people aged 65 years and over resident in NSW and who were living independently in the community. At least 500 older people were randomly selected from each of the 17 Area Health Services in NSW. The response rate for the survey was $70.7 \%{ }^{32}$. Survey weights were calculated to make the sample representative of the gender and age structure of older people in NSW overall ${ }^{34}$, and were also used in estimating proportions and for inferential statistical analyses presented here.

Along with sociodemographics, information on health, living arrangements, lifestyle and activity levels was collected $^{35}$. Owing to the wide range of health and wellbeing topics investigated, it was only feasible to include one item on food insecurity. For comparability, this item was worded as per the 1995 National Nutrition Survey ${ }^{30}$ : 'In the last 12 months, were there any times that you ran out of food and couldn't afford to buy more?' The question was designed to tap financial reasons for being unable to purchase food, rather than reasons of infirmity or distance from food sources or access to transport.

Responses were analysed by variables known to be associated with, or likely risk factors for, food insecurity: income and housing tenure (money situation, home ownership, private health insurance); health measures (self-rated health status, self-rated healthy lifestyle); living arrangement (living alone); gender; age; and type of location (small and large rural centres, urban). Age was divided into five categories: $64-69,70-74,75-79,80-84$ and $85+$ years; housing tenure as owner, renter, other; and living arrangement as 'lives alone' or 'lives with others'. Private health insurance was categorised as 'has private health insurance' yes/no. Responses on money situation were categorised as 'can't make ends meet', 'just enough to get along' or 'comfortable'. Self-rated health status was categorised as 'excellent', 'very good', 'good', 'fair' or 'poor', and the self-rated lifestyle item as 'very healthy', 'fairly healthy' or 'not so healthy'.

Univariate analyses and chi-square statistics were used to test for group differences. Raw survey numbers are reported here, but proportions and all statistical inferences were calculated based on applying the provided survey weights to the data, since the sample was selected originally on a stratified basis (500 respondents from each of the 17 Area Health Services). Predictors of an episode of food insecurity as a binary yes/no outcome were then modelled using logistic regression. Odds ratios for the factors hypothesised above to be associated with a food shortage episode, controlling for each other and for other confounding factors, were estimated. Confounding factors included gender, age and type of location.

\section{Results}

\section{Subgroup analyses}

A small minority of respondents $(n=206,2.0 \%)$ reported experiencing food insecurity in the previous 12 months, slightly higher in females (2.1\%) than males (1.8\%), but not significantly so $(P=0.32)$. There was no significant age trend for males, but in females decreasing proportions reported running out of food with increasing age, from $3.0 \%$ in the $65-69$ year age group, to $0.5 \%$ in the oldest age category of $85+$ years. The overall difference was significant across the female age groups $\left(\chi_{(4)}^{2}=21.5\right.$, $P=0.003)$, as was the decreasing trend with age $\left(\chi_{(1)}^{2}=13.0, P=0.0003\right)$.

Male respondents who reported running out of food were nine times more likely to report their health as 'poor' (4.6\%) than 'excellent' (0.5\%) (see Fig. 1). The positive trend in proportions of males reporting a food shortage with declining self-rated health was highly statistically significant $\left(\chi_{(1)}^{2}=25.1, P<0.0001\right)$, and consistent. In female respondents the trend in higher proportions reporting food insecurity with decreasing self-rated health

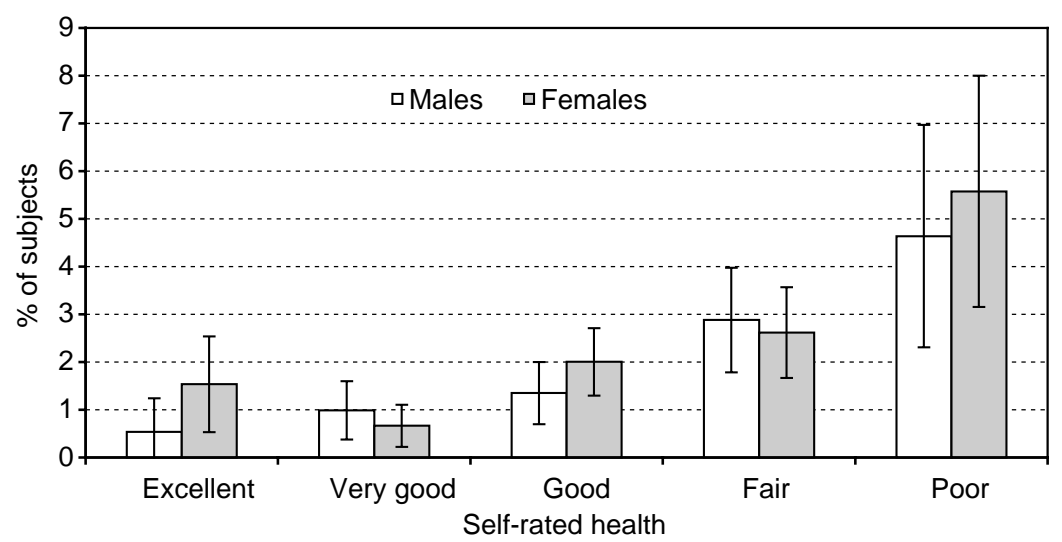

Fig. 1 Proportions (\%) of older people reporting a food shortage in the past 12 months, by self-rated health and gender, New South Wales Older Person's Health Survey 1999-2000 
was also statistically significant $\left(\chi_{(1)}^{2}=25.1, P<0.0001\right)$, but not as consistent as in the males.

Respondents who reported running out of food (see Table 1) were:

- Slightly, but not significantly, more likely to be living in 'urban' or 'large rural' centres (2.0\%) than in 'small rural' centres (1.5\%).

- Almost four times as likely to be renters (5.8\%) than home-owners (1.6\%), with the difference highly significant $\left(\chi_{(2)}^{2}=66.3, P<0.0001\right)$.

- Almost twice as likely to be living alone than with others (2.8\% vs. 1.5\%), with the difference highly significant $\left(\chi_{(1)}^{2}=19.1, P<0.0001\right)$.

- Almost six times more likely to rate their lifestyle as 'not so healthy' (6.4\%) as opposed to 'very healthy' (1.1\%). The overall difference was highly significant $\left(\chi_{(2)}^{2}=70.6, P<0.0001\right)$, as was the trend of increasing food insecurity with decreasing self-rated healthy lifestyle $\left(\chi_{(1)}^{2}=43.2, P<0.0001\right)$.

- Four times more likely to report needing 'household/personal help' (6.4\% vs. 1.6\%), with the difference highly significant $\left(\chi_{(1)}^{2}=78.2, P<0.0001\right)$.

- Nearly five times less likely to have private health insurance (0.6\% vs. 2.9\%), with the difference highly significant $\left(\chi_{(1)}^{2}=54.8, P<0.0001\right)$.
- Over 85 times more likely to report that they 'could not make ends meet' (26.3\%) than being financially 'comfortable' (0.3\%). The overall difference was very highly significant $\left(\chi_{(2)}^{2}=668.8, P<0.0001\right)$, and there was a highly significant trend of increasing proportions of food insecurity with worsening money situation category $\left(\chi_{(1)}^{2}=311.7, P<0.0001\right)$.

\section{Logistic regression model of predictors of reported food insecurity}

With confounding and other factors included in logistic regression models of reporting food insecurity, significant positive predictors of reporting a food shortage episode in male respondents were reporting struggling financially and having lower self-rated health. Living alone was a borderline significant positive risk factor, while having private health insurance was significantly negatively associated with reporting a food shortage in males. In female respondents, significant positive predictors of reporting a food shortage were being a renter, living alone, struggling financially and reporting a less healthy lifestyle. Significant negative predictors of a food shortage in female respondents were older age and having private health insurance. Three variables entered into the model were

Table 1 Numbers and proportions (\%) in each subgroup reporting a food shortage in the previous 12 months, New South Wales Older Person's Health Survey 1999-2000

\begin{tabular}{|c|c|c|}
\hline Group $(n=8881)$ & Food shortage, $n(\%)^{*}$ & $X^{2}, P$-value \\
\hline \multicolumn{3}{|l|}{ Sex } \\
\hline Males & $78(1.8)$ & $0.98(\mathrm{df}=1), 0.32$ \\
\hline Females & $128(2.1)$ & \\
\hline \multicolumn{3}{|l|}{ Location } \\
\hline Urban & $94(2.0)$ & $4.12(\mathrm{df}=3), 0.25$ \\
\hline Large, urbanised rural centre & $48(2.0)$ & \\
\hline Small rural centre & $49(1.5)$ & \\
\hline Other/Not specified & $15(3.0)$ & \\
\hline \multicolumn{3}{|l|}{ Housing tenure } \\
\hline Rents & $60(5.8)$ & $66.3(\mathrm{df}=2),<0.0001$ \\
\hline Owns & $137(1.6)$ & \\
\hline Other & $9(2.7)$ & \\
\hline \multicolumn{3}{|l|}{ Living arrangement } \\
\hline Lives alone & $129(2.8)$ & $19.1(\mathrm{df}=1),<0.0001$ \\
\hline Lives with others & 77 (1.5) & \\
\hline \multicolumn{3}{|l|}{ Private health insurance } \\
\hline Yes & $21(0.6)$ & $54.8(\mathrm{df}=1),<0.0001$ \\
\hline No & $185(2.9)$ & \\
\hline \multicolumn{3}{|l|}{ Financial situation } \\
\hline Can't make ends meet & $66(26.3)$ & $666.8(\mathrm{df}=2),<0.0001$ \\
\hline Just getting by & $123(2.8)$ & $311.7(\mathrm{df}=1),<0.0001($ trend $) \dagger$ \\
\hline Comfortable & $15(0.3)$ & \\
\hline No response & $2(4.1)$ & \\
\hline \multicolumn{3}{|l|}{ Need household/personal help } \\
\hline Yes & $45(6.4)$ & $78.2(\mathrm{df}=1),<0.0001$ \\
\hline No & $161(1.6)$ & \\
\hline \multicolumn{3}{|l|}{ Self-rated lifestyle } \\
\hline Not so healthy & $31(6.4)$ & $70.6(\mathrm{df}=2),<0.0001$ \\
\hline Fairly healthy & $128(2.1)$ & $43.2(\mathrm{df}=1),<0.0001($ trend $) \dagger$ \\
\hline Very healthy & $42(1.1)$ & \\
\hline No response & $5(7.1)$ & \\
\hline
\end{tabular}

* Proportions and chi-square statistics based on survey weights. †Non-response category excluded from trend test. 
not significant predictors of food insecurity, for either males or females: type of location, awareness of available services, and experiencing transport shopping problems.

\section{Discussion and conclusions}

Clear characteristics are associated with the increased likelihood of experiencing food insecurity. A not unexpected finding was that respondents who reported food insecurity were more likely to also report that they struggled financially to make ends meet. Poor self-rated health (males) and lifestyle (females) were also associated with higher probability of food insecurity and may reflect poorer health and lifestyle associated with lower resources.

While the majority of respondents (88.2\%) owned their own homes, the fact that those who rented were four times more likely to experience food insecurity highlights the plight of those people who continue to pay rent in their old age, which can constitute a sizeable proportion of their disposable income. That being a home-renter was a significant predictor of food insecurity in females, but not males, may be attributable to the more limited monetary resources available to older women. This finding is supported by literature which reports that women are less likely than men to have adequate resources in old age ${ }^{24}$ and hence women who are renting in old age would pay a higher proportion of their disposable income in rent than men.

Those respondents who owned their own dwelling (females), had private health insurance or enough money to get along or comfortably were less likely to report experiencing food insecurity, which is a finding that has strong face validity. Any of these factors would be an indicator of greater resources and/or income to avoid food insecurity.

The finding, stronger in females than males, that those who live alone are also more likely to experience food insecurity is consistent with the literature, and this potentially is an important risk factor at a population level, as almost two in every five $(38 \%)^{36}$ older people living independently in the community in NSW live alone. The decreased likelihood of food insecurity with increasing age, particularly in females, is interesting. A possible explanation is that increasing age is associated with reduced appetites ${ }^{37,38}$, so that food shortage is less likely if the amount of food required is less. Another possibility is that those who have managed to remain living to advanced old age in the community (rather than entering institutional care) are likely to have more family, neighbour, voluntary or other sources of care and assistance, which acts as a buffer against food insecurity. In general, women have wider informal social support networks than men ${ }^{39}$ and may therefore be better placed to obtain assistance from friends and family in hard financial times. It is also the case that those at greater nutritional risk are more likely to have entered an institution $^{40}$ or have died ${ }^{41}$, so that older old persons in the OPHS survey are those who are still living in the community and are survivors.

While this exploration of factors associated with food insecurity was based on one question, the inclusion of such a question in a large-scale epidemiological study means that responses could be analysed with respect to sociodemographic variables and with self-reported health and well-being to produce not only estimates of the size of the problem in the community, but also some of the characteristics of older people who experience it. Supportive data were also obtained from analysis of responses to two additional nutrition questions in the survey: 'How many serves of vegetables/fruit do you usually eat each day?' Those who reported food insecurity were significantly less likely to eat the recommended servings of vegetables. For males this was 2.03 servings compared with $3.02(P<0.03)$ and for females 2.20 versus. $3.05(P<0.01)$. For servings of fruit, the differences, while not significant, were in the expected direction: foodinsecure males 1.45 servings versus 1.73 , and for foodinsecure females 1.70 servings versus 1.93 . These findings emphasise the nutritional disadvantage faced by those who cannot afford to buy food, and are consistent with numerous studies conducted within poorer populations which repeatedly report lower fruit and vegetable consumption among food-insecure households ${ }^{12,42}$.

The overall finding that less than $2 \%$ of older people living independently in the community reported experiencing food insecurity due to insufficient money in the previous 12 months is positive; nevertheless, on a national basis, this translates to 47000 older people ${ }^{36}$ each year experiencing food insecurity through not being able to afford sustenance. The question on food insecurity in the OPHS used identical wording to the Australian National Nutrition Survey conducted in $1995^{30}$. The earlier survey reported a smaller percentage of people aged 65 and over experiencing food insecurity: $1.1 \%$ compared to $1.9 \%$, but the sample size for the national survey was considerably smaller than that for the state survey reported here (1960 nationally compared with 8881 in NSW). Given the smaller numbers and associated wider confidence intervals of the estimate of the national proportion reporting a food shortage, the estimates for the two surveys are not significantly different.

An important point to remember is that the small percentages reporting food insecurity on the basis of insufficient funds may underestimate somewhat the actual prevalence of food insecurity, as persons in this cohort of older Australians $(65+$ years $)$ are known to pride themselves on their self-sufficiency and ability to make do, and may be reluctant to admit that they could not afford to purchase food.

The method of data collection using a telephone may also have led to slight underreporting, although the connection 
rate in NSW is close to $100 \%$ and so is likely to have had minimal effect on the findings reported for those older people housed independently in the community. However, it is important to note that this survey did not include the most economically disadvantaged - the homeless, who, because they do not have a fixed abode (or land line telephone), are not represented in a general household population survey, and consequently the proportion of food-insecure in this age group overall is higher.

Our investigation focused specifically on food insecurity caused by inadequate finances. Other studies ${ }^{21,23,43}$ have considered food insecurity attributable to a range of causes, including infirmity causing inability to shop for food or transport it home. Thus the actual prevalence of food insecurity in this age group from all causes will be greater than that reported in our study, which sought to identify only those experiences of food insecurity directly attributable to inadequate finances.

Our analyses have estimated not only the size of the problem, but also some of the characteristics of those who experience it. Such people can be identified and are at risk of malnutrition and increased frailty, which in turn increases the likelihood of illness, falls, nursing home admission and death ${ }^{44}$. Thus, however 'residual' food insecurity may be in wealthy industrialised nations, it remains important for public health authorities to monitor the position and take relevant steps or urge governments to take appropriate and effective action. Alleviating the causes of food insecurity, particularly due to insufficient funds, is a feasible policy goal and is critical to reducing health inequalities ${ }^{19,22,31,45}$. As the NSW Centre for Public Health Nutrition ${ }^{3}$ notes: "When disposable income is limited, food is one of the first discretionary items to be pared ... indirect income support targeting non-food related costs, such as rent or mortgage repayments and bills, can assist households to redirect a greater proportion of disposable income to purchasing food' (p. 16).

\section{Acknowledgements}

The authors wish to thank the Epidemiology Branch of the NSW Department of Health who conducted the survey and gave us access to the OPHS dataset. The results presented in the present paper are based on analyses conducted independently by the authors. There is no conflict of interest.

\section{References}

1 Anderson SA. Core indicators of nutritional state for difficultto-sample populations. Journal of Nutrition 1990; 119(11): 1559-600.

2 Booth S, Smith A. Food security and poverty in Australia challenges for dieticians. Australian Journal of Nutrition and Dietetics 2001; 58(3): 150-6.

3 NSW Centre for Public Health Nutrition. Food Security Options Paper: A Planning Framework and Menu of Options for Policy and Practice Interventions. Sydney: NSW Department of Health, 2003.

4 Cohen BE, Burt MR. Eliminating Hunger: Food Security Policy for the 1990's. Washington, DC: The Urban Institute, 1989.

5 Radimer KL, Olson CM, Campbell CC. Development of indicators to assess hunger. Journal of Nutrition 1990; 120(Suppl. 11): 1544-8.

6 Food and Agriculture Organization of the United Nations (FAO). The State of Food Insecurity in the World 2003. Rome: FAO, 2003.

7 Nord M, Andrews M, Carlson S. Housebold Food Insecurity in the United States 2002. Food Assistance and Nutrition Research Report No. 35. Washington, DC: US Department of Agriculture, 2003.

8 Institute for the Study of Homelessness and Poverty. Hunger and Food Insecurity in Los Angeles. Los Angeles, CA: Institute for the Study of Homelessness and Poverty, 2001.

9 Bickel G, Carlson S, Nord M. Measuring Food Insecurity in the United States: Household Food Insecurity in the United States 1995-1998. Washington, DC: US Department of Agriculture, 1998.

10 Tarasuk VS. Household food insecurity with hunger is associated with women's food intakes, health and household circumstances. Journal of Nutrition 2001; 131(10): 2670-6.

11 Vozoris NT, Tarasuk VS. Household food insufficiency is associated with poorer health. Journal of Nutrition 2003; 133(1): 120-6.

12 Tingay R, Tan C, Tan N, Tang S, Teoh P, Wong R, et al. Food insecurity and low income in an English inner city. Journal of Public Health Medicine 2003; 25(2): 156-9.

13 Travers KD. The social organisation of nutritional inequities. Social Science \& Medicine 1996; 43(4): 543-53.

14 Campbell CC. Food insecurity: a nutritional outcome or a predictor variable? Journal of Nutrition 1991; 121(3): 408-15.

15 Parker SL. A national survey of nutritional risk among the elderly. Journal of Nutrition Education 1992; 24(1): 36S-45S.

16 Cook G, Reed J, Childs S, Hall A. Getting Old is Not for Cowards: Comfortable Healthy Ageing. York: James Rowntree Foundation, 2003.

17 Cook G, Reed J, Childs S, Hall A. Does Money Matter? Older People's Views of their Monetary Resources. York: James Rowntree Foundation, 2004.

18 Bridge C, Kendig H, Quine S, Parsons A. Housing and Care for Younger and Older Adults with Disabilities. Melbourne: Australian Housing and Urban Research Institute, 2002.

19 Smith GD, Brunner E. Socioeconomic differentials in health: the role of nutrition. Proceedings of the Nutrition Society 1997; 56(1A): 75-90.

20 Wolfe W, Olson CM, Kendall A, Frongillo EA. Understanding food insecurity in the elderly: a conceptual framework. Journal of Nutrition Education 1996; 28(2): 92-100.

21 Russell C, Touchard D, Kendig H, Quine S. Foodways to disadvantaged men growing old in the inner city. In: Weisstub DN, Thomasma DC, Gauthier S, Tomossy GF, eds. International Library of Ethics Law and New Medicine. Vol. 1. Ageing. Boston, MA: Kluwer, 2000; 191-215.

22 Whetstone M. Hard Times: A Study of Pensioner Poverty. London: Centre for Policy on Ageing, 2002

23 Wicks R, Trevena L, Quine S. Experiences of food insecurity amongst urban soup kitchen consumers: insights into improving nutrition and well-being. Journal of the American Dietetic Association 2005; in press.

24 Gibson D. The problem of old women redefined. In: Aged Care: Old Policies, New Problems. Cambridge: Cambridge University Press, 1998; 131-46. 
25 Lee JS, Frongillo EA. Nutritional and health consequences are associated with food insecurity among US older persons. Journal of Nutrition 2001; 131(5): 1503-9.

26 Cohen BE, Chapman N, Burt MR. Food sources and intake of homeless persons. Journal of Nutrition Education 1992; 24(1): $45 \mathrm{~S}-51 \mathrm{~S}$

27 Quine S, Kendig H, Russell C, Touchard D. Health promotion of socially disadvantaged groups: the case of older men. Health Promotion International 2004; 19(2): $157-65$.

28 Trevena L, Simpson J, Nutbeam D. Soup kitchen consumer perspectives on the quality and frequency of health service interactions. International Journal for Quality in Health Care 2003; 15(6): 495-500.

29 Quine S, Kendig H. Stakeholders in policy research for older Australians. Hallym International Journal of Aging 1999; 1(2): $16-25$

30 Australian Bureau of Statistics (ABS). National Nutrition Survey: Selected Highlights, Australia. Catalogue No. 4802.0. Canberra: ABS, 1997

31 Ginn J, Cooper H, Arber S. Inequalities in health-related behaviour among older people. In: Chiva A, Stears D, eds. Promoting the Health of Older People. Buckingham: Open University Press, 2001; 23-39.

32 NSW Department of Health. NSW Older People's Health Survey 1999. NSW Public Health Bulletin 2000; 11(Suppl. 2).

33 Baker D, Williamson M, Kendig H, Quine S. The 1999 NSW Older Persons Health Survey: an opportunity to monitor the health and well-being of older people in the community. NSW Public Health Bulletin 1999; 10(9): 113.

34 NSW Department of Health. The NSW Health Survey Program: overview and methods, 1996-2000. NSW Public Health Bulletin 2001; 12(Suppl. 2).

35 Quine S, Kendig H. Report on the Development of the Questionnaire for the NSW Older People's Health Survey. Sydney: NSW Department of Health, 2000.
36 Australian Institute of Health and Welfare (AIHW). Older Australians at a Glance. Canberra: AIHW, 2002.

37 Lipschitz DA, Nutrition. In: Cassel CK, Cohen HJ, Larson EB, Meir DE, Rubenstein LZ, et al., eds. Geriatric Medicine, 3rd ed. New York: Springer, 1997; 801-13.

38 Chernoff R. Effects of age on nutrient requirements. Clinical Geriatric Medicine 1995; 11(4): 641-51.

39 Kendig H. Family change and family bonding in Australia. In: Liu W, Kendig H, eds. Elderly Care, The Family and Human Values: East Meets West. Singapore: Singapore University Press, 2000; 107-25.

40 Payette H, Coulombe C. Nutritional risk factors for institutionalization in a free-living functionally dependent elderly population. Journal of Clinical Epidemiology 2000; 53: 579-87.

41 Australian Society for Geriatric Medicine. Australian Society for Geriatric Medicine Position Statement No. 6. Nutrition in the elderly. Australian Journal on Ageing 1997; 16: 174-8.

42 Lorenzana P, Sanjur D. Abbreviated measures of food insufficiency validly estimate the food insecurity level of poor households: measuring household food insecurity. Journal of Nutrition 1999; 129(3): 687-92.

43 Wolfe W, Frongillo E, Valois P. Understanding the experience of food insecurity by elders suggests ways to improve its measurement. Journal of Nutrition 2003; 133(9): 2762-9.

44 Salkeld G, Cameron I, Cumming R, Easter S, Seymour J, Kurrle S, et al. Quality of life related to fear of falling and hip fracture in older women: a time trade-off study. British Medical Journal 2000; 320(7231): 341-5.

45 Davey Smith G, Dorling D, Gordon D, Shaw M. The widening health gap: what are the solutions?. In: Davey Smith G, ed. Health Inequalities: Life Course Approaches. Bristol: The Policy Press, 2003; 453-7. 